\title{
A HALANAY-TYPE INEQUALITY ON TIME SCALES IN HIGHER DIMENSIONAL SPACES
}

\author{
BAOguo JiA, Lynn ERbE AND RAZIYE MerT
}

Abstract. In this paper, we investigate a certain class of Halanay-type inequalities on time scales in higher dimensional spaces. By means of the obtained inequality, we derive some new global stability conditions for linear delay dynamic systems on time scales. An example is given to illustrate the results.

Mathematics subject classification (2010): 34K11, 39A10, 39A99. equality.

Keywords and phrases: Delay dynamic equation, dynamic inequality, global stability, Halanay in-

\section{REFERENCES}

[1] R. P. Agarwal, Difference Equations and Inequalities, Marcel Dekker, New York, 2000.

[2] R. P. Agarwal, S. R. GRACE AND D. O'Regan, Oscillation Theory for Difference and Functional Differential Equations, Kluwer Academic Publishers, Netherlands, 2000.

[3] Christopher T. H. BAKer, Development and application of Halanay-type theory: Evolutionary differential and difference equations with time lag, J. Comput. Appl. Math 2234 (2010), 2663-2682.

[4] A. Halanay, Differential Equations Stability, Oscillation, Time Lags, Academic Press, New York and London, 1965, 377-383.

[5] D. D. SiluaK, Large Scale Dynamic Systems: Stability and Structure, New York: North-Holland, 1978, 394-404.

[6] Murat Adivar, Elvan Akin Bohner, Halanay type inequalities on time scales with applications, Nonlinear Analysis, 74 (2011), 7519-7531.

[7] S. Mohamad And K. Gopals amy, Continuous and discrete Halanay-type inequalities, Bull. Austral. Math. Soc., 61 (2000), 371-385.

[8] M. Bohner And A. Peterson, Dynamic Equation on Time Scales: An Introduction with Applications, Birkhäuser, Boston, 2001.

[9] M. Bohner And A. Peterson, editors, Advances in Dynamic Equations on Time Scales, Birkhäuser, Boston, 2003.

[10] M. Bohner, Some oscillation criteria for first order delay dynamic equation, Far East J. Appl. Math. 18 (2005), 289-304. 